\title{
Case report of EUS-guided endoscopic transduodenal necrosectomy in a patient with sleeve gastrectomy
}

\author{
Avik Sarkar $^{1 *}$, Ragui Sadek², Matthew Lissauer ${ }^{2}$ and Swati Pawa ${ }^{1}$
}

\begin{abstract}
Background: After an acute attack of pancreatitis, walled-off pancreatic fluid collections (PFC) occur in approximately $10 \%$ of cases. Drainage of the cavity is recommended when specific indications are met. Endoscopic drainage has been adopted as the main intervention for symptomatic walled-off PFC. Altered gastric anatomy in these patients poses an interesting challenge. We present the first case of a patient with sleeve gastrectomy who underwent successful endoscopic transduodenal necrosectomy (TDN).
\end{abstract}

Case presentation: Forty year old woman with history of morbid obesity status post sleeve gastrectomy in 2009 was found to have symptomatic gallstone disease complicated by severe necrotizing gallstone pancreatitis and further complicated by symptomatic walled off pancreatic necrosis (WOPN). Imaging significant for $10.8 \times 7.6 \mathrm{~cm}$ fluid collection with necrotic debris in the body and tail of the pancreas and endoscopic necrosectomy was attempted. EGD showed tubular gastric body and antrum, with extrinsic compression in the antrum and duodenal bulb from the pancreatic cyst. Duodenal bulb was selected as the preferred fistula site due to sleeve gastrectomy. Patient underwent successful TDN in two sessions. Patient had symptomatic improvement at follow-up with resolution of WOPN.

Conclusion: To our knowledge, this is the first reported case of EUS-guided endoscopic necrosectomy in a patient with sleeve gastrectomy. The duodenal approach was used in our patient due to history of sleeve gastrectomy.

Keywords: Sleeve gastrectomy endoscopic necrosectomy, Altered gastric anatomy endoscopic necrosectomy

\section{Background}

After an attack of severe acute pancreatitis, walled-off pancreatic fluid or necrotic collections occur in nearly $10 \%$ of cases [1]. Decompression is recommended in symptomatic patients with abdominal pain, gastric outlet or biliary obstruction, fluid leakage, fistulization, weight loss or failure to thrive, and infection [2, 3]. Controversy exists regarding initial therapy but endoscopic ultrasound (EUS) guided transmural drainage has been adopted as the first line therapy for symptomatic pseudocysts and walled off pancreatic necrosis (WOPN) given its similar

\footnotetext{
* Correspondence: avik.sarkar@rwjms.rutgers.edu

${ }^{1}$ Division of Gastroenterology, Department of Internal Medicine, Rutgers Robert Wood Johnson Medical School, 1 Robert Wood Johnson Place, Medical Education Building Room 478, New Brunswick, NJ 08901, USA Full list of author information is available at the end of the article
}

efficacy, shorter recovery times, low rate of adverse events and improved cost-effectiveness compared with surgical cystgastrostomy [2, 4-8]. Endoscopic treatment outcomes are directly related to the type of pancreatic fluid collection (PFC) being treated; while the treatment success for pancreatic pseudocysts is greater than $90 \%$, it is 50 to $65 \%$ for WOPN $[9,10]$. With this method, the puncture route with the shortest distance between the gastrointestinal tract and the wall of the cyst is chosen under EUS guidance, and most often this is a transgastric approach. A large bore needle is used to access the identified pseudocyst or WOPN, creating a fistula between the cystic cavity and the gastrointestinal tract [11]. In cases of altered gastric anatomy, there may be technical difficulty due to limited space and patients may require surgical or laparoscopic cystgastrostomy [12]. We present 
an index case of a patient with sleeve gastrectomy who underwent successful endoscopic transduodenal necrosectomy (TDN).

\section{Case presentation}

A 40 year old woman with a past medical history significant for morbid obesity status post sleeve gastrectomy in 2009 presented with intermittent post-prandial right upper quadrant abdominal pain consistent with symptomatic gallstone disease and was recommended for cholecystectomy. In the interim the patient developed severe necrotizing gallstone pancreatitis, which was complicated by symptomatic WOPN. At 4 week followup, imaging revealed a large hyperintense on T2 and hypointense on $\mathrm{T} 1$ fluid collection with solid components seen in the body and tail of the pancreas measuring approximately $10.8 \times 7.6 \mathrm{~cm}$. Follow-up imaging at week 8 showed that the WOPN was compressing the distal stomach and duodenum with symptoms of gastric outlet obstruction (Figs. 1, 2, 3 and 4). After a multidisciplinary meeting involving surgery and interventional radiology, endoscopic necrosectomy was recommended. Esophagogastroduodenosocpy (EGD) revealed a tubular gastric body and part of the antrum, with extrinsic compression in the antrum and duodenal bulb from the WOPN (Fig. 5). The preferred fistula site was in the duodenal bulb due to distance from sleeve, cyst location and desire to avoid the staple line (Figs. 6 and 7). The patient underwent successful TDN (Figs. 8 and 9) with placement of three $10 \mathrm{Fr}$ pigtail stents (Fig. 10). At 3 month follow-up, patient did well with resolution of WOPN and removal of pigtail stents.

\section{Conclusion}

To our knowledge, this is the first reported case of a patient with sleeve gastrectomy undergoing successful

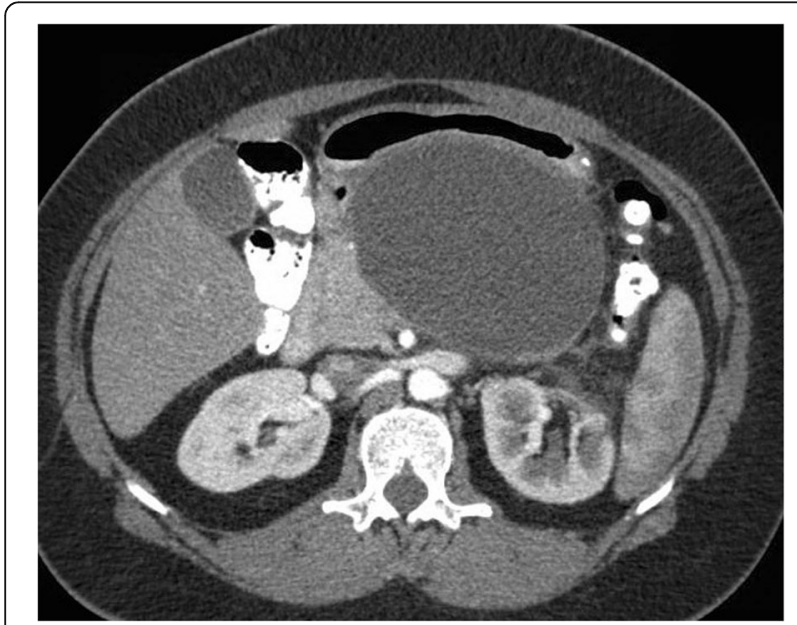

Fig. 1 Duodenal compression (axial CT image)

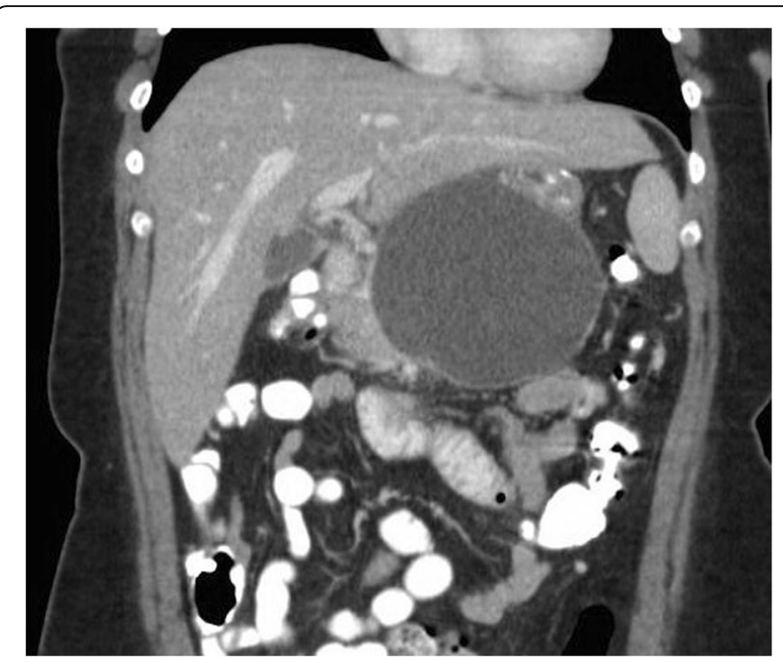

Fig. 2 WOPN imaging (coronal CT image)

endoscopic pancreatic cyst drainage and necrosectomy. Although the transgastric approach is preferred for walled-off pancreatic fluid collections due to location of the collection being more favorable and the comfort level of endoscopists, there is no definite evidence that transgastric drainage is superior to transduodenal drainage [13]. Long-term patency of transduodenal drainage tracts may reduce the recurrence rate of pancreatic pseudocysts. After the creation of a sleeve, there is increased intraluminal pressure, which incidentally is also thought to play a role in leaks along the staple line [14-17]. Specifically, a study measured the volume and pressure for both the resected stomach and the remaining sleeve and demonstrated the distensibility of the resected portion is 10-fold higher than the gastric sleeve with a significantly lower intraluminal pressure $[18,19]$. They were able to conclude that the mechanism of restriction following the sleeve gastrectomy is the combination of the small capacity, low distensibility, and the resultant immediate high intraluminal pressure [19]. The duodenal approach was

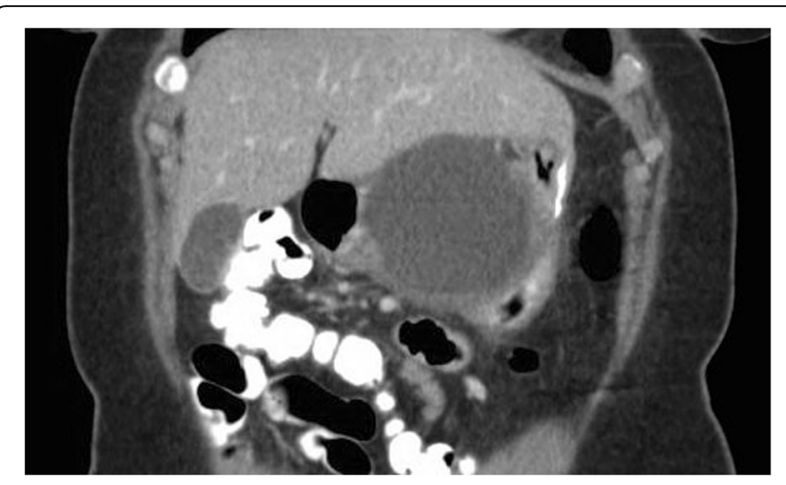

Fig. 3 Sleeve compression (coronal CT image) 


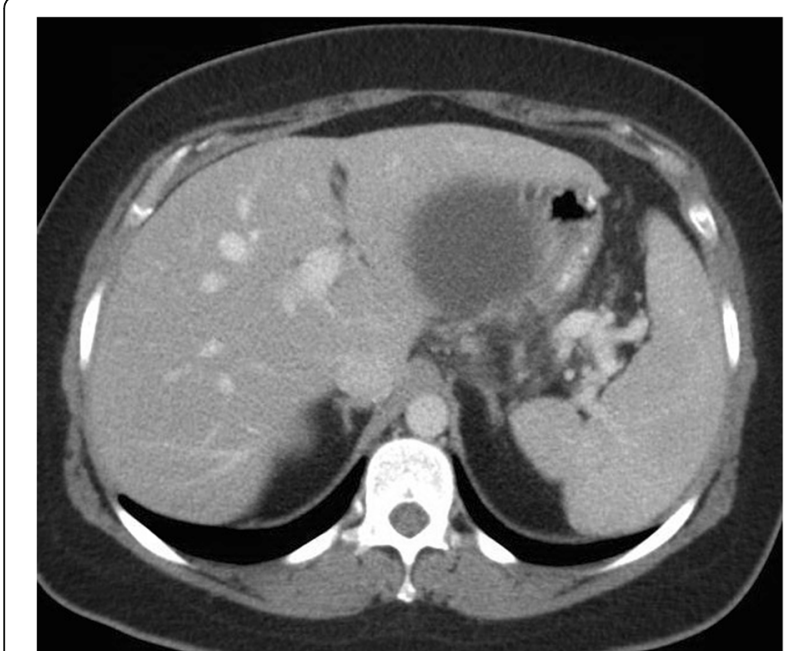

Fig. 4 Sleeve compression (axial CT image)

used in our patient to avoid the high pressure in the sleeve stomach that may lead to inadequate drainage, as fluid is known to preferentially flow from a highpressure area to a low-pressure area. Conversely, recent studies have shown success with drainage of peritoneal fluid collections from sleeve gastrectomy leaks using endoscopically placed pigtail stents, similar to the procedure used for drainage of symptomatic pancreatic fluid collections [20-22]. Although this method has been successful for leaks, this may be aided by the leak-induced disruption of the increased intraluminal pressure and therefore may not be generalizable to draining PFCs into the sleeve.

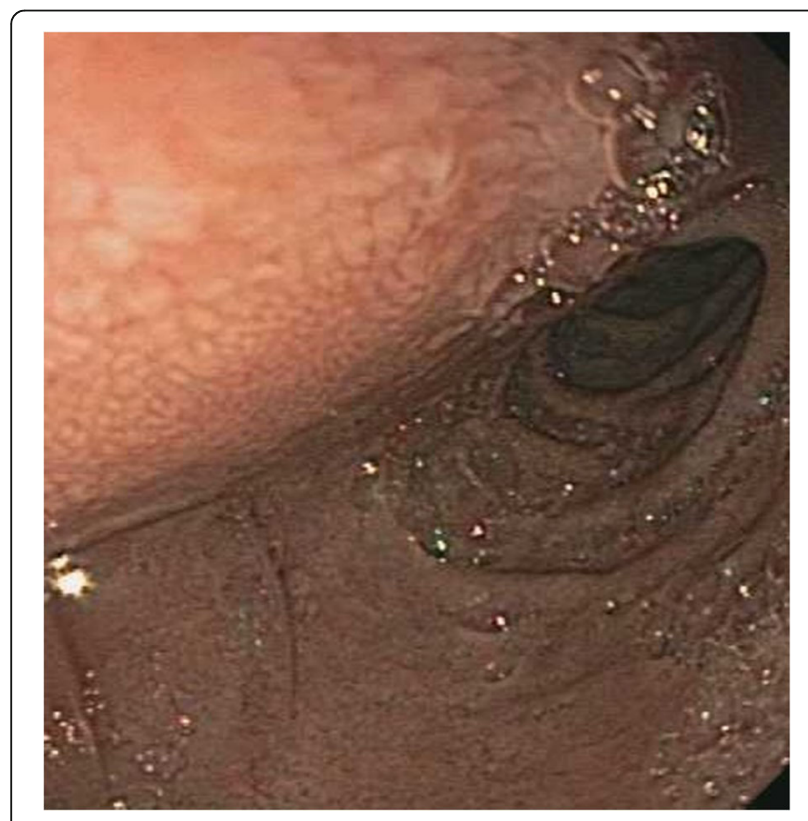

Fig. 5 Duodenal bulb extrinsic compression from WOPN

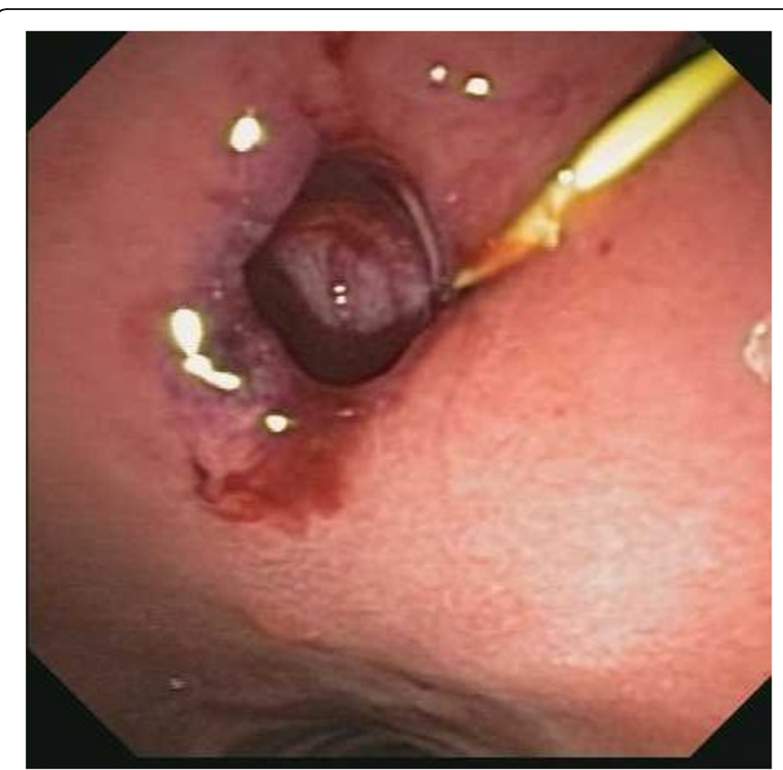

Fig. 6 Fistula creation*

Additionally, manipulation nearby the staple line may lead to an anastomotic leak and disruption of the staple line and should be avoided. Another potential location of drainage of PFCs in this patient population is the preserved portion of the antrum. The duodenal bulb was chosen over the antrum in our patient due to the cyst location and desire to maintain distance from the staple line.

Review of literature revealed one similar case with a failed attempt at endoscopic cyst-gastrostomy due to limited working space and the inability to visualize the posterior aspect of the stomach given sleeve

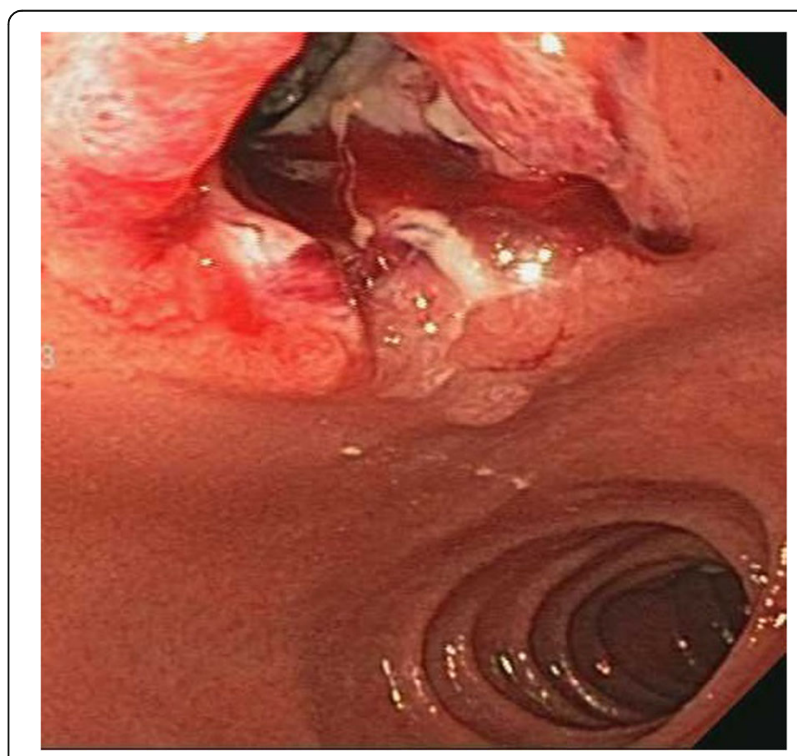

Fig. 7 Fistula* 


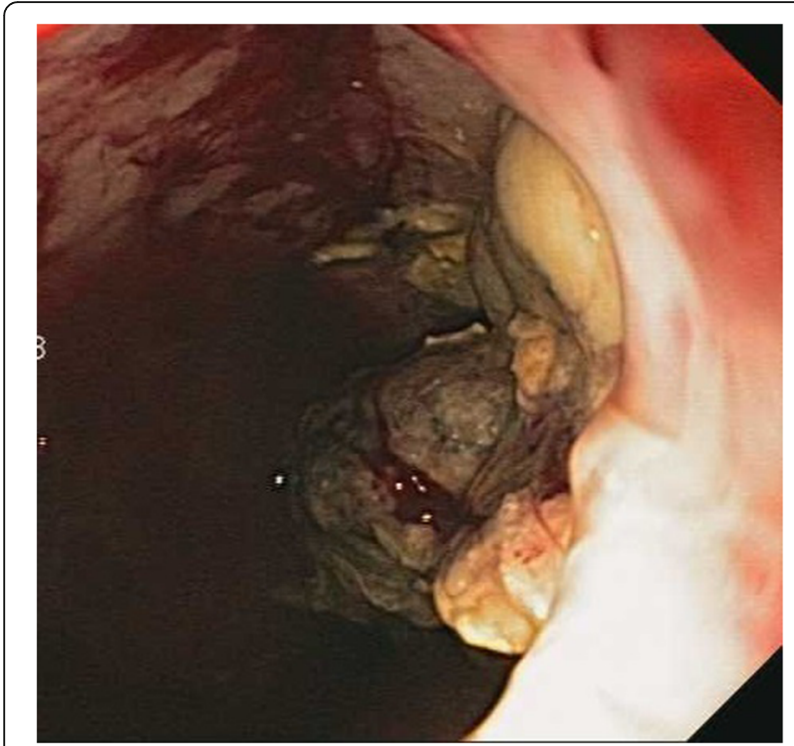

Fig. 8 WOPN cavity*

gastrectomy [12]. Although the surgical approach is an adequate intervention for these patients, randomized trials have validated similar outcomes between endoscopic and surgical pancreatic pseudocyst drainage, with endoscopic treatment linked with reduced hospital stays, improved physical and mental health of patients, and decreased cost $[6,23]$. This case illustrates the feasibility of endoscopic drainage and necrosectomy for WOPN in patients with altered gastric anatomy through EUS-guided TDN [24].

CARE guidelines were adhered to in the publication of this manuscript [25].

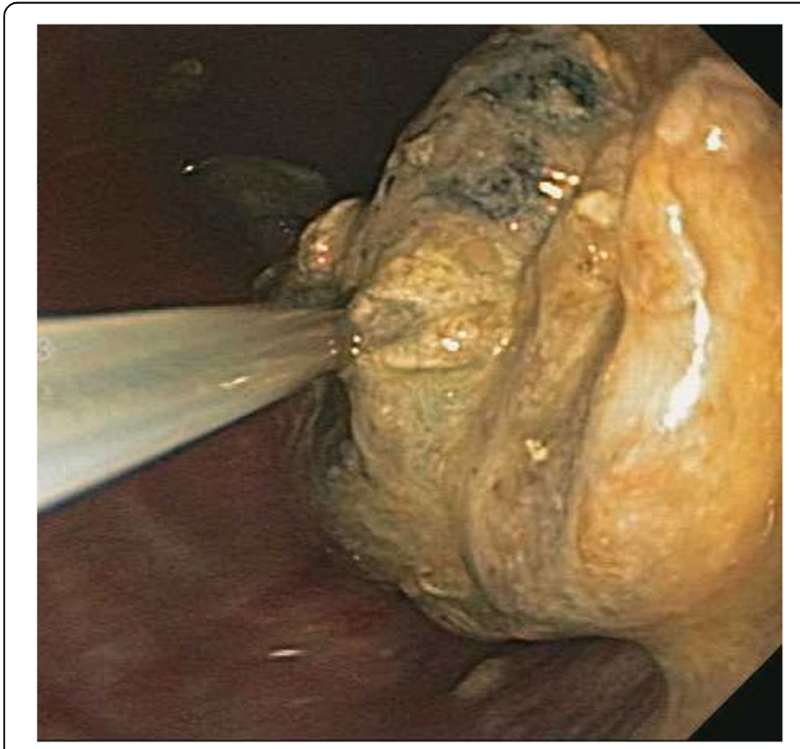

Fig. 9 Necrosectomy

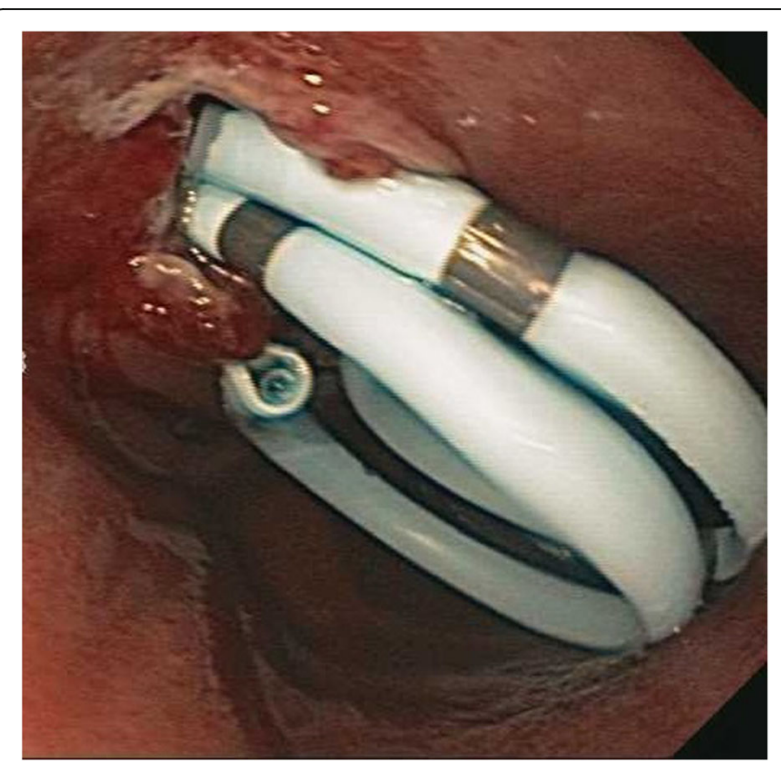

Fig. 10 Stent placement

\section{Abbreviations}

EUS: Endoscopic ultrasound; WOPN: Walled off pancreatic necrosis; PFC: Pancreatic fluid collection; TDN: Transduodenal necrosectomy; EGD: Esophagogastroduodenosocpy; CT: Computed tomography; Fr: French

\section{Acknowledgements}

N/a.

Funding

N/a.

\section{Availability of data and materials}

N/a.

\section{Authors' contributions}

AS evaluated the patient, participated in the procedures, drafted the abstract and manuscript. RS evaluated the patient, participated in the procedures, edited the abstract and manuscript. ML evaluated the patient, participated in the procedures, edited the abstract and manuscript. SP evaluated the patient, participated in the procedures, edited the abstract and manuscript. All authors read and approved the final manuscript.

\section{Competing interests}

The authors declare that they have no competing interests.

\section{Consent for publication}

Consent to publish was obtained from the patient using the consent form.

\section{Ethics approval and consent to participate}

As this was a case report, no IRB is required by our institution.

\section{Author details}

'Division of Gastroenterology, Department of Internal Medicine, Rutgers Robert Wood Johnson Medical School, 1 Robert Wood Johnson Place, Medical Education Building Room 478, New Brunswick, NJ 08901, USA.

${ }^{2}$ Department of Surgery, Rutgers - Robert Wood Johnson Medical School, New Brunswick, NJ, USA.

Received: 6 November 2015 Accepted: 6 September 2016 Published online: 13 September 2016 


\section{References}

1. O'Malley VP, Cannon JP, Postier RG. Pancreatic pseudocysts: cause, therapy, and results. Am J Surg. 1985;150(6):680-2.

2. Kokosis $\mathrm{G}$, et al. Review of complications associated with endoscopic pancreatic cyst-gastrostomy: a single-institution experience. Surg Laparosc Endosc Percutan Tech. 2015;25(3):245-9.

3. Jacobson BC, et al. ASGE guideline: The role of endoscopy in the diagnosis and the management of cystic lesions and inflammatory fluid collections of the pancreas. Gastrointest Endosc. 2005;61(3):363-70.

4. Baron TH, Kozarek RA. Endotherapy for organized pancreatic necrosis: perspectives after 20 years. Clin Gastroenterol Hepatol. 2012;10(11):1202-7.

5. Freeman $\mathrm{ML}$, et al. Interventions for necrotizing pancreatitis: summary of a multidisciplinary consensus conference. Pancreas. 2012;41(8):1176-94.

6. Varadarajulu S, et al. Equal efficacy of endoscopic and surgical cystogastrostomy for pancreatic pseudocyst drainage in a randomized trial. Gastroenterology. 2013;145(3):583-90.

7. van Santvoort HC, et al. A step-up approach or open necrosectomy for necrotizing pancreatitis. N Engl J Med. 2010;362(16):1491-502.

8. Bakker OJ, et al. Endoscopic transgastric vs surgical necrosectomy for infected necrotizing pancreatitis: a randomized trial. JAMA. 2012;307(10):1053-61.

9. Bang JY, Varadarajulu S. Metal versus Plastic Stent for Transmural Drainage of Pancreatic Fluid Collections. Clin Endosc. 2013:46(5):500-2.

10. Varadarajulu S, et al. Endoscopic transmural drainage of peripancreatic fluid collections: outcomes and predictors of treatment success in 211 consecutive patients. J Gastrointest Surg. 2011;15(11):2080-8.

11. Mukai S, Itoi T, Moriyasu F. Interventional endoscopy for the treatment of pancreatic pseudocyst and walled-off necrosis (with videos). J Hepatobiliary Pancreat Sci. 2014;21(10):E75-85.

12. Halawani HM, Alami RS, Abi Saad GS. Laparoscopic cyst-gastrostomy after laparoscopic sleeve gastrectomy. Surg Obes Relat Dis. 2015;11(4):975-7.

13. Yusuf TE, Baron TH. Endoscopic transmural drainage of pancreatic pseudocysts: results of a national and an international survey of ASGE members. Gastrointest Endosc. 2006:63(2):223-7.

14. Moszkowicz D, et al. Sleeve gastrectomy severe complications: is it always a reasonable surgical option? Obes Surg. 2013;23(5):676-86.

15. Benedix $F$, et al. Are there risk factors that increase the rate of staple line leakage in patients undergoing primary sleeve gastrectomy for morbid obesity? Obes Surg. 2014;24(10):1610-6.

16. Timucin Aydin M, et al. Staple Line Reinforcement Methods in Laparoscopic Sleeve Gastrectomy: Comparison of Burst Pressures and Leaks. Jsls, 2015; 19(3)1-6.

17. Abou Rached A, Basile M, El Masri H. Gastric leaks post sleeve gastrectomy: Review of its prevention and management. World J Gastroenterol. 2014; 20(38):13904-10.

18. Toro JP, et al. Observed Variability in Sleeve Gastrectomy Volume and Compliance Does Not Correlate to Postoperative Outcomes. Surg Laparosc Endosc Percutan Tech. 2015;25(4):324-30.

19. Yehoshua RT, et al. Laparoscopic sleeve gastrectomy-volume and pressure assessment. Obes Surg. 2008;18(9):1083-8.

20. Donatelli $\mathrm{G}$, et al. Endoscopic Internal Drainage with Enteral Nutrition (EDEN) for treatment of leaks following sleeve gastrectomy. Obes Surg. 2014;24(8):1400-7.

21. Pequignot $A$, et al. Is there a place for pigtail drains in the management of gastric leaks after laparoscopic sleeve gastrectomy? Obes Surg. 2012:22(5):712-20.

22. Slim R, et al. Endoscopic stenting of gastric staple line leak following sleeve gastrectomy. Obes Surg. 2013;23(11):1942-5.

23. Akshintala VS, et al. A comparative evaluation of outcomes of endoscopic versus percutaneous drainage for symptomatic pancreatic pseudocysts. Gastrointest Endosc. 2014;79(6):921-8. quiz 983.e2, 983.e5.

24. Sarkar A, Sadek R, Lissauer M, Tilara A, Pawa S. EUS-quided Endoscopic Transduodenal Necrosectomy in a Patient With Sleeve Gastrectomy. Am J Gastroenterol. 2015;110(S1):S117.

25. Gagnier JJ, et al. The CARE guidelines: consensus-based clinical case reporting guideline development. BMJ Case Rep. 2013. 2013;1-4.

\section{Submit your next manuscript to BioMed Central and we will help you at every step:}

- We accept pre-submission inquiries

- Our selector tool helps you to find the most relevant journal

- We provide round the clock customer support

- Convenient online submission

- Thorough peer review

- Inclusion in PubMed and all major indexing services

- Maximum visibility for your research

Submit your manuscript at www.biomedcentral.com/submit 